\title{
Reconstrução cirúrgica por biomateriais: uma revisão integrativa de literatura
}

\author{
Surgical reconstruction using biomaterials: an integrative literature review \\ Reconstrucción quirúrgica con biomateriales: revisión integradora de la literature
}

Recebido: 01/09/2021 | Revisado: 09/09/2021 | Aceito: 09/09/2021 | Publicado: 12/09/2021

Sofia Brandão Torres Silva
ORCID: https://orcid.org/0000-0003-1254-2053
Centro Universitário de Patos de Minas, Brasil
E-mail: soso_brandao@ hotmail.com
Andressa Ferreira Andrade
ORCID: https://orcid.org/0000-0002-9546-6596
Centro Universitário de Patos de Minas, Brasil
E-mail: andressafa@ unipam.edu.br
Bárbara Queiroz de Figueiredo
ORCID: https://orcid.org/0000-0003-1630-4597
Centro Universitário de Patos de Minas, Brasil
E-mail: barbarafigueiredo@ unipam.edu.br
Flávia Garcia Freitas
ORCID: https://orcid.org/0000-0002-7457-0693
Centro Universitário de Patos de Minas, Brasil
E-mail: flaviagarcia250@ gmail.com
Luísa Babilônia Barcelos
ORCID: https://orcid.org/0000-0002-5517-5153
Centro Universitário de Patos de Minas, Brasil
E-mail: luisabarcelos@ unipam.edu.br
Maria Luísa Alves Peres
ORCID: https://orcid.org/0000-0002-5528-6478
Centro Universitário de Patos de Minas, Brasil
E-mail: marialuisa1@ @unipam.edu.br
Rayane Cristina Neves Dias Silvano
ORCID: https://orcid.org/0000-0001-5672-3169
Centro Universitário de Patos de Minas, Brasil
E-mail: rayanejk @ hotmail.com
Rafael Sávio Soares

\section{Resumo}

Introdução: os biomateriais têm por definição qualquer substância biocompatível, que não seja droga, sintética ou natural, que por um período complete, aumente ou substitua a função de um tecido ou órgão, sendo utilizados em pós trauma. Objetivo: verificar, dentro da literatura existente, quais são os biomateriais disponíveis e suas melhores formas de utilização na reconstrução cirúrgica. Metodologia: consiste em uma revisão integrativa de literatura sobre reconstrução cirúrgica por biomateriais, a partir do estabelecimento das palavras-chave da pesquisa, foi realizado o cruzamento dos descritores "biomateriais"; "materiais biocompatíveis/uso terapêutico"; "enxerto"; "cirurgia plástica/reabilitação"; "bioengenharia", nas seguintes bases de dados: dados National Library of Medicine (PubMed MEDLINE), Scientific Electronic Library Online (Scielo), Cochrane Database of Systematic Reviews (CDSR), Google Scholar, Biblioteca Virtual em Saúde (BVS) e EBSCO Information Services, no mês de agosto de 2021, sendo considerados estudos publicados no período compreendido entre 2008 e 2021. Resultados e discussão: segundo os resultados coletados, a partir dos artigos científicos, há uma grande disponibilidade de biomateriais para reconstrução, onde cada tipo pode beneficiar diferentes indivíduos. Considerando a gama de biomateriais disponíveis, há uma disponibilidade diferente para cada um, mas a finalidade é trazer benefícios ao processo regenerativo aos indivíduos. Conclusão: fica sob responsabilidade do profissional optar pela melhor biomaterial disponível individualmente a cada paciente e condição clínica.

Palavras-chave: Biomateriais; Cirurgia plástica; Reconstrução.

\section{Abstract}

Introduction: Biomaterials have by definition any biocompatible substance, which is not a drug, synthetic or natural, that for a complete period, increases or replaces the function of a tissue or organ, being used in post trauma. Objective: to verify, within the existing literature, which are the biomaterials available and their best ways to be 
used in surgical reconstruction. Methodology: it consists of an integrative literature review on surgical reconstruction using biomaterials, based on the establishment of the research keywords, the crossing of the descriptors "biomaterials" was performed; "biocompatible materials/therapeutic use"; "graft"; "plastic surgery/rehabilitation"; "bioengineering", in the following databases: National Library of Medicine (PubMed MEDLINE), Scientific Electronic Library Online (Scielo), Cochrane Database of Systematic Reviews (CDSR), Google Scholar, Virtual Health Library (BVS) and EBSCO Information Services, in August 2021, considering studies published in the period between 2008 and 2021. Results and discussion: according to the results collected from scientific articles, there is a wide availability of biomaterials for reconstruction, where each type can benefit different individuals. Considering the range of biomaterials available, there is a different availability for each one, but the purpose is to bring benefits to the regenerative process to individuals. Conclusion: it is up to the professional to choose the best biomaterial available individually for each patient and clinical condition.

Keywords: Biomaterials; Plastic surgery; Reconstruction.

\begin{abstract}
Resumen
Introducción: Los biomateriales tienen por definición cualquier sustancia biocompatible, que no sea una droga, sintética o natural, que por un período completo, aumenta o reemplaza la función de un tejido u órgano, siendo utilizada en postraumatismo. Objetivo: verificar, dentro de la literatura existente, cuáles son los biomateriales disponibles y sus mejores formas para ser utilizados en la reconstrucción quirúrgica. Metodología: consiste en una revisión integradora de la literatura sobre reconstrucción quirúrgica utilizando biomateriales, a partir del establecimiento de las palabras clave de investigación, se realizó el cruce de los descriptores "biomateriales"; "Materiales biocompatibles / uso terapéutico"; "injerto"; "Cirugía plástica / rehabilitación"; "Bioingeniería", en las siguientes bases de datos: datos de la Biblioteca Nacional de Medicina (PubMed MEDLINE), Biblioteca Electrónica Científica en Línea (Scielo), Base de Datos Cochrane de Revisiones Sistemáticas (CDSR), Google Scholar, Biblioteca Virtual de Salud (BVS) y Servicios de Información de EBSCO, en agosto de 2021, considerando estudios publicados en el período comprendido entre 2008 y 2021. Resultados y discusión: de acuerdo a los resultados recolectados de artículos científicos, existe una amplia disponibilidad de biomateriales para reconstrucción, donde cada tipo puede beneficiar a diferentes individuos. Teniendo en cuenta la gama de biomateriales disponibles, existe una disponibilidad diferente para cada uno, pero el propósito es aportar beneficios al proceso regenerativo a los individuos. Conclusión: corresponde al profesional elegir el mejor biomaterial disponible de forma individual para cada paciente y condición clínica.
\end{abstract}

Palabras clave: Biomateriales; Cirugía plástica; Reconstrucción.

\title{
1. Introdução
}

O trauma é muito presente nos hospitais, ele é uma das principais causas de mortalidade e morbidade. Os traumas geram repercussões traumáticas físicas, emocionais e possibilidade de lesões irreversíveis, causando um grande dano no paciente. (Colombo, 2010). O diagnóstico por meio de exame clínico dos pacientes que sofreram traumas é facilitado devido a presença de edemas e deformidades. No entanto, é necessário fazer o exame de imagem, como a tomografia computadorizada, para um diagnostico certeiro. (Mendonça, 2011). Assim, essa realidade evidencia a importância da reconstrução cirúrgica.

Uma das técnicas utilizadas na reconstrução cirúrgica estrutural facial é o a dos biomateriais. Esses são usados em diversas aplicações médicas e tem por definição sendo qualquer material que substitui ou amplia uma função natural de uma parte ou de toda uma estrutura vida ou também de um dispositivo biomédico. (Maia, 2010). Alguns exemplos de biomateriais como dispositivo biomédico são os tubos de circulação sanguínea, sistemas de hemodiálise, e como materiais implantáveis podem-se citar as suturas, placas e telas. (Pires, 2015). Ademais, uma das vantagens de utilizar os biomateriais é que evita o uso de enxertos, como os músculos, ossos, diminuindo a morbidade dos doadores, além de abrandar deformidades e dores. Além disso, diminui o tempo de cirurgia, otimizando a prática médica. Os biomaterias são fabricados com materiais com grande disponibilidade, com composições conhecidas, e a preferência do médico é um critério de seleção do biomaterial que irá ser utilizado. (Maia, 2010).

Porém, é necessário avaliar os matérias para saber se esses têm critérios, que não irá ter repercussões para o corpo. É importante ficar atento a taxa de degradação, a biocompatibidade, biodegrabilidade e biorreabsorbilidade. A 
biocompatibilidade assegura que os matérias serão seguros para a utilização. Os materiais biocompativeis são aqueles que não provocam reação infamatória, é necessário ter uma imunogenicidade. Um fator importante para evitar a reação é a superfície dos biomateriais. Os materiais biodegradáveis podem ser degradados com tempo, sendo de duas formas: degradação hidrolítica e degradação enzimática. A degradação hidrolítica ocorre pela água, já a degradação enzimática ocorre pela ação de enzimas. Os materiais biorrreabsorvíveis são degradáveis, assim não necessitam de segunda cirurgia para remover os implantes. (Anderson, 2008).

Além do mais, reconstrução por biomateriais é muito vantajoso, pela sua facilidade de manuseio, eles podem adquirir forma de acordo com a necessidade. Dessa maneira, eles têm uma grande adaptação, facilitando a cirurgia. Contudo, também há desvantagens, como o elevado custo, por serem materiais que não são produzidos no Brasil. (Maia, 2010). Contém uma grande variedade de materiais, sendo classificados em grupos, como cerâmica, polímeros e metais. Os de cerâmica incluem os hidroxiapatita e cimentos, sendo muito bons para a reconstrução estrutural, eles não impedem a reabsorção. O polietileno poroso é o mais comum e mais utilizado do grupo dos polímeros, esse permite o crescimento interno. Já do grupo dos metais, o titânio é praticamente o único utilizado, eles são usados para fixação rígida, tendo grande resistência e estabilidade. Ademais, contém os biomateriais osteoativos como a matriz de osso desmineralizada, com reposição e com pouca precisão de contorno (Maia, 2010).

Sendo assim, haja vista a relevância da reconstrução cirúrgica por biomateriais, o presente estudo tem como objetivo, por meio de revisão de literatura, com caráter sistemático, mostrar a importância do uso dos biomateriais na pratica cirúrgica, evidenciando suas repercussões.

\section{Metodologia}

O presente estudo consiste em uma revisão integrativa de literatura sobre reconstrução cirúrgica por biomateriais, a partir do estabelecimento das palavras-chave da pesquisa, foi realizado o cruzamento dos descritores "biomateriais"; "materiais biocompatíveis/uso terapêutico"; "enxerto"; "cirurgia plástica/reabilitação"; "bioengenharia", nas seguintes bases de dados: dados National Library of Medicine (PubMed MEDLINE), Scientific Electronic Library Online (Scielo), Cochrane Database of Systematic Reviews (CDSR), Google Scholar, Biblioteca Virtual em Saúde (BVS) e EBSCO Information Services, no mês de agosto de 2021, sendo considerados estudos publicados no período compreendido entre 2008 e 2021 .

A estratégia de seleção dos artigos seguiu as seguintes etapas: busca nas bases de dados selecionadas; leitura dos títulos de todos os artigos encontrados e exclusão daqueles que não abordavam o assunto; leitura crítica dos resumos dos artigos e leitura na íntegra dos artigos selecionados nas etapas anteriores.

Como critérios de inclusão, foram considerados artigos originais, que abordassem o tema pesquisado e permitissem acesso integral ao conteúdo do estudo, publicados no período de 2008 a 2021, em inglês, português e espanhol. O critério de exclusão foi imposto naqueles trabalhos que não estavam em inglês, português e espanhol, que não tinham passado por processo de Peer-View e que não abordassem a temática do estudo. A estratégia de seleção dos artigos seguiu as seguintes etapas: busca nas bases de dados selecionadas; leitura dos títulos de todos os artigos encontrados e exclusão daqueles que não abordavam o assunto; leitura crítica dos resumos dos artigos e leitura na íntegra dos artigos selecionados nas etapas anteriores. Assim, totalizaram-se 22 artigos científicos para a revisão integrativa da literatura, com os descritores apresentados acima, dos últimos dezenove anos e em línguas portuguesa, inglesa e espanhola. 


\section{Resultados e Discussão}

Após a seleção dos artigos por meio dos critérios de inclusão e de exclusão, elaborou-se um quadro (Quadro 1), contendo as principais informações sobre a utilização de biomateriais em cirurgias reconstrutivas, baseada nos diversos artigos analisados e no ano de publicação. Desta maneira, facilitou-se a visualização dos resultados para melhor discussão da temática. Logo, é possível visualizar que, dentre os artigos listados, há uma grande variedade de materiais disponíveis para o uso em reconstruções cirúrgicas, então cabe a cada profissional conhecer as suas características e as técnicas existentes, para que, dessa forma, seja possível oferecer a cada paciente o melhor tratamento baseando-se em suas próprias características e individualidades clínicas.

Quadro 1: Informações dos artigos selecionados.

\begin{tabular}{|c|c|c|}
\hline AUTOR & ANO & ACHADOS PRINCIPAIS \\
\hline Rodrigues, W. J. P. R. & 2014 & $\begin{array}{l}\text { Nesta revisão sistemática, constata-se que a associação das técnicas cirúrgicas minimamente } \\
\text { invasivas aos biomateriais são positivas. Por outro lado, em relação à associação de diferentes } \\
\text { biomateriais às técnicas não foram demonstrados benefícios adicionais, de acordo com os estudos } \\
\text { utilizados. }\end{array}$ \\
\hline Horn, K. S. & 2011 & $\begin{array}{l}\text { Nesta revisão de literatura, contata-se que os biomateriais utilizados no estudo apresentam } \\
\text { comportamentos semelhantes na regeneração óssea em implantes fenestrados e favorável } \\
\text { osseointegração. }\end{array}$ \\
\hline Castro, E. K. O., et al. & 2018 & $\begin{array}{l}\text { Nesta revisão de literatura, evidencia-se a eficácia da utilização de biomateriais para preenchimento } \\
\text { em áreas atróficas em região posterior da maxila. Além disso, constata-se que o osso autógeno é } \\
\text { apontado, majoritariamente entre os autores, como padrão ouro devido a sua compatibilidade e a } \\
\text { capacidade de reparação }\end{array}$ \\
\hline Rafael Junior, J. C., et al. & 2020 & $\begin{array}{l}\text { Neste relato de caso, é demonstrado que a utilização de matriz suína como fonte de colágeno no } \\
\text { tratamento de recessão gengival do tipo RT1 apresenta resultados positivos para o paciente, além de } \\
\text { oferecer para o profissional uma ferramenta eficiente em procedimentos cirúrgicos reconstrutivos. }\end{array}$ \\
\hline Matta, R. K. A., et al. & 2020 & $\begin{array}{l}\text { Neste relato de caso envolvendo reconstrução fronto-orbital, evidencia-se que no meio cirúrgico a } \\
\text { escolha do biomaterial a ser utilizado varia entre os profissionais devido ao fato de não haver um } \\
\text { critério de seleção. }\end{array}$ \\
\hline Maia, M., et al. & 2010 & $\begin{array}{l}\text { A utilização de biomateriais para a reconstrução facial em substituição aos materiais autogênicos } \\
\text { ocorre em uma escala cada vez mais ampla. Apesar de existirem muitas opções no mercado, um } \\
\text { critério na seleção para determinar a escolha dos biomateriais nos diversos tipos de reconstruções } \\
\text { ainda não foi estabelecido, e o seu uso em cirurgias faciais não é bem definido. Usualmente, a } \\
\text { preferência pessoal é o fator determinante da escolha dos biomateriais. Quando o cirurgião conhece } \\
\text { as propriedades exatas, as vantagens e as desvantagens e também como manusear os biomateriais } \\
\text { nas reconstruções faciais, seu campo de atuação se expande na mesma proporção. }\end{array}$ \\
\hline Colombo, L. R. C., et al. & 2010 & $\begin{array}{l}\text { No artigo, é abordada a utilização de biomateriais para reconstrução orbitária, destacando que para a } \\
\text { escolha do material ideal para cada fratura deve-se analisar os resultados a longo prazo e a } \\
\text { experiência do cirurgião. }\end{array}$ \\
\hline Turrer, C. L., et al. & 2007 & $\begin{array}{l}\text { Neste artigo, ao analisar o uso de compósito de biocerâmica em matriz polimérica a } 10 \% \text { em } \\
\text { cirurgias de reconstrução do complexo zigomático orbitário, constata-se que o material possui } \\
\text { capacidade de biointegração ao sítio receptor e que é uma opção favorável para o reposicionamento } \\
\text { e a devolução do contorno da órbita com objetivos de recuperação de volume e reabilitação. }\end{array}$ \\
\hline Leite, W. B., et al. & 2018 & $\begin{array}{l}\text { Nesta revisão de literatura, observa-se a avalição dos diversos tipos de biomateriais na produção de } \\
\text { próteses que farão parte da recuperação da articulação do quadril em artroplastias. }\end{array}$ \\
\hline $\begin{array}{l}\text { Barbosa, M. C. S. A., et } \\
\text { al. }\end{array}$ & 2018 & $\begin{array}{l}\text { Nesta revisão de literatura, são evidenciados os principais tipos de biomateriais utilizados em } \\
\text { procedimentos de artroplastia pacial ou total da articulação temporomandibular. }\end{array}$ \\
\hline Rodrigues, L. B. & 2013 & $\begin{array}{l}\text { Neste estudo, observa-se a abordagem do uso de biomateriais em ortopedia, mencionando } \\
\text { conceitos, materiais utilizados e suas aplicações. }\end{array}$ \\
\hline $\begin{array}{l}\text { Martín-Del-Campo, M., } \\
\text { et al. }\end{array}$ & 2019 & $\begin{array}{l}\text { O artigo aborda o uso de compostos de baixo peso molecular para a regeneração de fissura labial e } \\
\text { palatina. }\end{array}$ \\
\hline
\end{tabular}




\begin{tabular}{|c|c|c|}
\hline Zhang, Q., et al. & 2019 & $\begin{array}{l}\text { No artigo, é abordado o uso de biomateriais em cirurgias de reparo e de reconstrução de defeitos } \\
\text { mandibulares. Evidencia-se que cada método e material tem sua vantagem particular, situação que } \\
\text { impossibilita o estabelecimento de um modelo como opção mais ideal. }\end{array}$ \\
\hline Das, S, et al. & 2016 & $\begin{array}{l}\text { O artigo retrata o avanço do uso de biomateriais e da nanoterapia com o propósito de utilizar no } \\
\text { processo de cicatrização de feridas na pele, pois atualmente não existem biomateriais aprovados que } \\
\text { liberem componentes bioativos que influenciem diretamente a cascata de cicatrização de feridas. }\end{array}$ \\
\hline Colazo, J. M., et al. & 2019 & $\begin{array}{l}\text { Neste artigo, aborda-se a reconstrução de tecidos, substituição e regeneração a partir do uso da } \\
\text { bioengenharia. }\end{array}$ \\
\hline Pires, A. L. R., et al. & 2015 & $\begin{array}{l}\text { Neste artigo, é abordado um compilado de biomateriais disponíveis, destacando-se os scaffolds - } \\
\text { com aplicações na engenharia tecidual e culturas de células tronco e dispositivos customizados, } \\
\text { adaptáveis ou apropriados para situações em que o indivíduo se encontra em crescimento. }\end{array}$ \\
\hline $\begin{array}{l}\text { Mendonça, J. C. G., et } \\
\text { al. }\end{array}$ & 2011 & $\begin{array}{l}\text { Neste relato de caso, são abordadas condutas perante fraturas faciais partindo de um caso de fratura } \\
\text { no terço médio da face com utilização de placas e parafusos de titânio para redução das fraturas. }\end{array}$ \\
\hline Anderson, J. M., et al. & 2009 & $\begin{array}{l}\text { No artigo, aborda-se as reações e os resultados no organismo a partir da incorporação de corpos } \\
\text { estranhos. }\end{array}$ \\
\hline França, V. P., et al. & 2005 & $\begin{array}{l}\text { No artigo, estabeleceu-se comparação experimental de compósito bioativo de matriz polimérica e } \\
\text { Medpor® e Polipore } ® \text {, visando aplicação cirúrgica na substituição tecidual ocular, evidenciando } \\
\text { maior efetividade dos compósitos. }\end{array}$ \\
\hline Turrer, C. L., et al. & 2008 & $\begin{array}{l}\text { Biomateriais são materiais de origem biológica ou sintética, possuindo múltiplas aplicações ou } \\
\text { finalidades. Os principais biomateriais aplicados na cirurgia craniomaxilofacial podem ser divididos } \\
\text { em três classes: metais, cerâmicas (incluem carbonos, vitro-cerâmicas e biovidros) e polímeros. }\end{array}$ \\
\hline Claudino, J., et al. & 2019 & $\begin{array}{l}\text { Com a necessidade de reconstruções dos tecidos ósseos perdidos, levou-se ao aprimoramento } \\
\text { técnico ao avanço dos estudos de tais materiais que pudessem substituir ou aperfeiçoar os } \\
\text { procedimentos de enxertia em humanos. Além disso, a origem destes materiais, sejam eles } \\
\text { autógenos, alógenos, xenógenos ou aloplásticos, apresentam indicações precisas para que se tenha } \\
\text { sucesso. }\end{array}$ \\
\hline de Paula, B. L., et al. & 2017 & $\begin{array}{l}\text { Na área da odontologia a utilização de biomateriais como substitutos de tecido mole é de suma } \\
\text { importância na prática clínica, tanto no aspecto estético como na promoção da saúde, uma vez que o } \\
\text { enxerto autógeno de gengiva possui inúmeras limitações. }\end{array}$ \\
\hline Signori, P. H., et al. & 2016 & $\begin{array}{l}\text { De acordo com o artigo, não há comprovações científicas que direcionem para um padrão de } \\
\text { materiais a serem utilizados em cirurgias de reconstrução do assoalho orbitário. }\end{array}$ \\
\hline Pilger, A. D., et al. & 2018 & $\begin{array}{l}\text { No material, evidencia-se que a escolha do biomaterial varia diante das diversas técnicas cirúrgicas } \\
\text { e do tipo disponível, cabendo ao profissional a escolha do melhor ao se basear nas evidências } \\
\text { científicas que relatam as vantagens e desvantagens que cada pode oferecer ao tratamento. }\end{array}$ \\
\hline Leal, T. R., et al. & 2016 & $\begin{array}{l}\text { A revisão de literatura aborda a utilização da Regeneração Tecidual Guiada (RTG) para a } \\
\text { reconstrução periodontal com a utilização de membranas não reabsorvíveis, pois apresentam } \\
\text { facilidade de posicionamento e de contorno do defeito. }\end{array}$ \\
\hline Silva, V. V. & 2017 & $\begin{array}{l}\text { Na prática ortopédica, ao escolher um biomaterial, deve-se atentar a sua capacidade de suportar a } \\
\text { agressividade corrosiva do meio fisiológico, além de permitir suporte físico para a migração, adesão } \\
\text { e diferenciação das células durante a neoformação óssea, remodelação e integração com o tecido ao } \\
\text { qual está sendo implantado. }\end{array}$ \\
\hline
\end{tabular}

Fonte: Autoria própria, 2021

De acordo com Rodrigues (2013), biomaterial pode ser definido como qualquer substância (outra que não droga) ou combinação de substâncias, sintética ou natural em origem, que possa ser usada por um período de tempo, completa ou parcialmente como parte de um sistema que trate, aumente ou substitua qualquer tecido, órgão ou função do corpo. Como características primordiais, tal matéria deve ser biocompatível e não produzir nenhuma resposta infecciosa ou alérgica no organismo. Além disso, o autor aborda a respeito dos vários materiais que podem ser utilizados, sendo eles: metais e ligas metálicas, polímeros, cerâmicos e compósitos. 
Sob essa perspectiva, segundo Anderson, et al. (2009), deve-se atentar à química da superfície do biomaterial, pois ela pode impactar os comportamentos dos macrófagos, como a adesão, a apoptose, a fusão e a secreção de citocinas. Nesse sentido, destaca-se a interação entre o hospedeiro e as células singênicas, alogênicas ou xenogênicas que são submetidas, no local do implante, a mediadores inflamatórios e moléculas de sinalização que são diferentes do ambiente nativo das células de construção e dependendo do tipo de célula no implante, esses mediadores podem evocar respostas variáveis, como ativação, diferenciação, proliferação ou migração. Além disso, as células próximas ou na superfície do material seriam submetidas a um ambiente de baixo pH, ROS e enzimas degradativas que são específicas para a reação de corpo estranho. Portanto, para que os híbridos material-célula tenham um desempenho ideal, seria necessária a modulação específica da reação de corpo estranho, fornecendo um ambiente biomimético adequado para garantir a sobrevivência das células além de direcionar os comportamentos celulares desejados ao implante. Os materiais xenógenos - retirados de uma espécie e transplantados para outra exigem um tratamento mais vigoroso do enxerto com o objetivo de prevenir a ocorrência de rejeição, enquanto os aloplásticos, normalmente produzidos em laboratórios, visam assegurar a biocompatibilidade dos materiais no organismo humano, a fim de evitar rejeição ou infecção (Claudino et al. 2019).

Para que um material seja favorável para enxertia óssea é necessário que ele seja totalmente reabsorvível e substituído por novo tecido ósseo, não gerando resposta inflamatória e alérgica. Destaca-se também que apesar de o uso de enxerto autógeno ser apontado como padrão ouro ao considerar neoformação óssea e aceitação do organismo, outros materiais também podem ser utilizados mantendo a qualidade, pois a reconstrução óssea é complexa e diversificada, não havendo uma regra. Somado a isso, observa-se que o uso de biomateriais para preenchimento de áreas atróficas em região posterior da maxila é eficaz, além de ser fundamental que o profissional analise individualmente cada caso e selecione o material mais favorável em conjunto com a técnica a ser utilizada, visando à manutenção das funcionalidades fisiológicas e anatômicas além de propiciar o retorno da forma e das características habituais (Castro et al. 2018).

Materiais autógenos como ossos e cartilagens demonstra resistência além de possibilitar a incorporação do tecido adjacente e vascularização, sendo favorável nas reconstruções de órbita, apresentando como desvantagens uma taxa de reabsorção imprevisível que varia entre 20 e 75\% e a necessidade de um sítio operatório posterior. Destaca-se como principais fontes de enxertos a calota craniana, a crista ilíaca, as costelas, a parede de seio maxilar e a mandíbula. A utilização de cartilagem do septo nasal para esse fim limita-se a casos de pequenos defeitos de órbita, pois como o material tende a arquear menos há maior dificuldade de suportar o conteúdo intraorbitário e com isso ocorre aumento das chances de ocorrerem posteriores complicações (Colombo et al. 2010). Além disso, Colombo et al. (2010), aborda também a possibilidade de utilizar materiais provenientes de cadáveres e animais de outras espécies para a reconstrução orbital utilizando crista ilíaca, costela, cartilagem, dura-máter e fáscia lata liofilizada. Tais materiais podem apresentar características osteocondutoras, apesar de a revascularização e a integração ocorrer mais lentamente em comparação com materiais autógenos. Encontra-se como empecilho a possibilidade de transmissão de infeções e o potencial antigênico, mesmo com a aplicação de técnicas de esterilização, situação que deve ser amplamente monitorada.

Além disso, os materiais autógenos como ossos e cartilagens demonstra resistência além de possibilitar a incorporação do tecido adjacente e vascularização, sendo favorável nas reconstruções de órbita, apresentando como desvantagens uma taxa de reabsorção imprevisível que varia entre 20 e $75 \%$ e a necessidade de um sítio operatório posterior. Destaca-se como principais fontes de enxertos a calota craniana, a crista ilíaca, as costelas, a parede de seio maxilar e a mandíbula. A utilização de cartilagem do septo nasal para esse fim limita-se a casos de pequenos defeitos de órbita, pois como o material tende a arquear menos há maior dificuldade de suportar o conteúdo intraorbitário e com isso ocorre aumento das chances de ocorrerem posteriores complicações (Colombo et al. 2010). 
Os biomateriais podem se apresentar de duas formas: em grânulos e em blocos, e a forma granular porosa é a mais usual devido à praticidade e à baixa resistência dos biomateriais em blocos, que são passíveis de sofrerem fraturas durante a fixação. Nos materiais de maior porosidade nota-se uma certa vantagem em relação ao menos porosos, pois facilitam a migração e proliferação celular, assim como o transporte nutritivo da engenharia de tecido ósseo. Deve-se levar em consideração o volume de osso autógeno necessário, pois quando há um grande volume exigido, os tecidos alógenos podem ser uma alternativa, apesar de que as diferentes áreas doadoras alógenas não apresentam uma constância na taxa de formação óssea. Por outro lado, os biomateriais de origem xenógena apresentam uma vasta documentação na literatura, tanto na sua capacidade osteocondutiva, quanto na condução de uma regeneração óssea previsível (Pilger et al., 2018).

De acordo com Rodrigues (2014), ao utilizar biomateriais em técnicas cirúrgicas minimamente invasivas para tratamento de defeitos ósseos periodontais, é possível obter melhorias nas taxas de cicatrização, no aumento da conservação do contorno e da altura do tecido mole. Além disso, há observações de que o procedimento proporciona melhor bem-estar para o paciente, pois a dor e o desconforto pós-operatório são mínimos ou inexistentes. Com base nos estudos selecionados, não houve indicação de benefícios adicionais da associação de diferentes biomateriais às técnicas cirúrgicas em questão, desse modo, cabe a realização de estudos e comparações mais específicas e profundas. Assim, o uso de biomateriais mostra-se favorável tanto para o profissional quanto para o receptor do produto.

Estudo de Horn (2011) relata que na implantodontia há ocorrência de feitos ósseos que necessitam de reparo tanto anteriormente a cirurgia implantar, quanto em casos de fenestração óssea trans-cirúrgica. Nesse sentido, é possível aplicar a regeneração óssea guiada (ROG), na qual utiliza-se biomateriais capazes de influenciar seletivamente a formação óssea, propiciando um procedimento bem sucedido, com baixos risco e em resultados com o menor número possível de intervenções cirúrgicas. Nessa técnica, utiliza-se como biomateriais o material de preenchimento ósseo, membranas reabsorvíveis e o próprio implante, buscando estabilidade, posicionamento adequado, neoformação óssea e manutenção do volume ósseo a longo prazo, sendo necessário para isso propriedades ostegênicas e baixa taxa de substituição. No entanto, apesar de as avaliações demonstrarem resultados positivos para a osseointegração dos biomateriais utilizados, estudos revelam que nenhum dos substitutos ósseos disponíveis são capazes de suprir ambos os aspectos, situação que demanda aprofundamento de pesquisas.

De acordo com Rafael Junior et al. (2020), ao utilizar o biomaterial Mucoderm ${ }^{\circledR}$ - matriz suína tridimensional, estável e constituída de colágeno e elastina - em tratamento cirúrgico de recessões gengivais múltiplas RT1, obteve-se como resultado um satisfatório recobrimento radicular, redução do tempo clínico cirúrgico e também uma cicatrização mais confortável para o paciente. Desse modo, evidencia-se que tal biomaterial é uma alternativa viável ao uso de enxerto autógeno, pois é ilimitado e fornece ao paciente segurança e efetividade. Por outro lado, constata-se que é necessário realizar mais estudos para esclarecer o possível potencial de remodelação tecidual tardio desses biomateriais.

Segundo Matta et al. (2020), atualmente, apesar de serem encontrados diversos biomateriais passíveis de serem utilizados nas reconstruções faciais em substituição de enxertos autógenos, a escolha do biomaterial segue a preferência pessoal do profissional visto que não há um critério norteador. Além disso, contata-se que a redução cirúrgica cruenta por acesso hemicoronal proporciona amplo campo operatório e cicatriz cirúrgica escondida por pelos do couro cabeludo.

Como observado por Maia et al. (2010), os biomateriais são boas opções aos procedimentos cirúrgicos reconstrutivos e obliterativos da região fronto-orbitária, sendo necessário atentar-se ao fato de que o esforço de tração dos músculos da região gera carregamento variável em diferentes regiões. Além disso, pontua que materiais biodegradáveis, como os polímeros, são vantajosos em relação aos metais devido a possibilidade de redução da capacidade de tensão acumulada, o alívio de dores e a eliminação da necessidade de realizar procedimentos posteriores visando à remoção dos implantes metálicos. 
Já segundo Leite et al. (2018), as próteses ortopédicas aplicadas ao quadril podem ser compostas por diferentes materiais, dentre eles os mais utilizados atualmente são os pares tribológicos metal-polietileno, cerâmica-polietileno e cerâmica-cerâmica. Nesse sentido para a escolha do melhor biomaterial é indicado uma avaliação individual de cada paciente considerando materiais que tenham alta resistência, baixo desgaste, resistência à corrosão e baixo atrito, além de serem biocompatíveis. Ademais, o resultado satisfatório da cirurgia estará diretamente relacionado a escolha adequada da técnica cirúrgica a ser utilizada.

Ao utilizar conjuntamente materiais reabsorvíveis e não reabsorvíveis em pacientes que sofreram trauma facial, observa-se boa estabilização e restauração do contorno sem enxertos de osso cranial e redução da quantidade de componentes aloplásticos permanentes. Ademais, a hidroxiapatita e os cimentos de fosfato de cálcio, classificados como cerâmica, apresentam-se como uma possibilidade em reconstrução facial devido ao fato de não impedirem a reabsorção de longo prazo. No entanto, esses materiais não possuem um significativo crescimento interno ósseo, sendo recomendados, então, para reconstrução sobre camadas e como osteocondutivos como recrutadores de osteoblastos do esqueleto adjacente para a reposição óssea ao longo do tempo (Maia et al. 2020). O enxerto com hidroxiapatita é uma boa escolha como biomaterial complementar a reconstrução craniofacial, apresentando um resultado estético favorável e estável mantendo bom contorno do arcabouço fronto-orbital e auxiliando na manutenção funcional de todas as estruturas anatômicas envolvidas no complexo. (Matta et al., 2020)

Segundo Pilger et al. (2018) a hidroxiapatita, composto presente em alguns biomateriais, é interessante por manter a estabilidade dimensional na área operada ou manutenção volumétrica do rebordo alveolar durante a regeneração óssea, devido ao fato de apresenta reabsorção lenta. Por outro lado, estudos apontam que tal característica pode dificultar a neoformação óssea, situação que deve ser melhor explorada. Ainda, segundo Maia, et al. (2020), a matriz de osso desmineralizada e os vidros bioativos apresentam reposição óssea significativa, mas com menor precisão de contorno e formato em comparação com os cimentos e os polímeros.

O polietileno poroso permite o crescimento interno vascular e de tecido mole após uma semana e crescimento interno ósseo após três semanas, e é indicado em reconstruções sobre camadas e entre camadas de segmentos que não estejam sujeitos a pressão, como na reconstrução ou preenchimento da região maxilofacial. Ademais, a utilização de metais carrega preocupação em relação a corrosão e liberação de íons no corpo, atrofia óssea, afrouxamento do dispositivo e sensibilidade pela temperatura (Maia et al. 2020).

Os biomateriais metálicos utilizados na ortopedia possuem satisfatório desempenho mecânico, mas passam por corrosão resultante da interação com o meio fisiológico, situação que pode ser minimizada por meio da passivação da superfície do implante com recobrimento da superfície do implante com material não corrosivo (cerâmico, polimérico ou óxido) para impedir o intercâmbio iônico. Além disso, constatou-se que ao inserir poros ou funcionalização da superfície metálica com materiais osteocondutivos é possível reduzir a diferença entre as propriedades mecânicas do implante e do osso, fornecendo também a adesão no sítio de implante (Silva, 2017).

Segundo Signori et al. (2010) dois fatores são fundamentais nas reconstruções da porção interna da órbita: o material utilizado e a habilidade em recriar a anatomia local. Mas como não há comprovações cientificas de superioridade de um material sobre outro no ponto de vista das reações desencadeadas nos tecidos periorbitários, cabe ao cirurgião ter o controle apenas sobre a habilidade em recriar a anatomia interna da orbita. Deve-se destacar que a magnitude da fatura é o fator crítico para a seleção de um biomaterial na reconstrução do assoalho orbitário, desse modo, as telas de Márlex ${ }^{\circledR}$ são recomendadas para fraturas de pequeno tamanho $\left(\right.$ até $\left.1 \mathrm{~cm}^{2}\right)$ do assoalho orbitários, e para defeitos de maior proporção $\left(\right.$ acima de $\left.1 \mathrm{~cm}^{2}\right)$ é recomendado a utilização de telas de titânio, dando uma maior rigidez estrutural, com o propósito de evitar o colapso do 
conteúdo orbitário e corrige a posição do globo ocular.

Segundo Leal et al. (2018), há evidências claras de que existem vantagens na recorrência à terapia de Regeneração Tecidual Guiada (RTG) nos defeitos intraósseos e de furca. Cabe ao profissional distinguir a real necessidade de cada paciente, respeitando a limitação individual e a própria estrutura de intervenção, delineando a melhor estratégia e adequando o biomaterial, de modo a aperfeiçoar o processo regenerativo. De acordo com Turrer et al (2008), em seu estudo comparativo a respeito de reconstrução da órbita por meio de implante de compósito de biocerâmica em matriz polimérica a $10 \%$, constatou que houve melhora do contorno e da projeção do conjunto órbito-zigomático, além de não ter havido reações inflamatórias locais durante o período de acompanhamento. Observou-se também que o edema presente nos casos estudados passou por regressão completa entre o vigésimo e trigésimo dia de pós-operatório, restringindo-se somente ao sítio operatório.

Materiais porosos como polímeros e biocerâmicas indicados para a reconstrução do esqueleto crânio facial possuem grande disponibilidade e podem ser alterados durante a cirurgia para que possuam uma conformação espacial ideal para o local receptor - ossos autógenos não apresentam esta maleabilidade para adaptar-se ao local desejado. Atualmente, existem materiais disponíveis em comercialização que podem ser usados para reparação do esqueleto facial com boa integração e biocompatibilidade (Turrer et al. 2008). De acordo com Matta et al. (2020), a reconstrução do complexo frontoorbital fora do leito cirúrgico ofereceu uma certa facilidade no manuseio dos fragmentos ósseos e modelagem das placas e microtela.

A utilização de próteses na articulação temporomandibular (ATM) apresentaram vantagens em relação aos enxertos autógenos, de forma que evidenciaram menos complicações e redução do tempo cirúrgico total. Nesse viés, são abordados uma variedade de biomateriais utilizados em próteses de ATM, sendo eles: o Vitallium que é uma liga de cromo, cobalto e molibdênio, sendo bem aceito para uso ortopédico em seres humanos como substituto de articulações, o Polietpolietileno de Ultra-Alto Peso Molecular (PUAPM) que pode ser utilizado como componente da fossa articular devido a propriedades como biocompatibilidade, módulo de elasticidade próximo ao osso e baixos coeficientes de atrito e desgaste e por fim, a Liga de Titânio que tem recebido uma atenção devido às suas propriedades mecânicas, resistência à corrosão. Além disso, algumas características foram elencadas para que as próteses sejam recomendadas, são elas: biocompatibilidade, funcionalidade, leveza, adaptabilidade, estabilidade, ser resistente à corrosão e também deve ser atóxica (Barbosa et al. 2018).

De acordo com Barbosa et al. (2018), alguns outros materiais foram descartados em procedimentos de artroplastia total da articulação temporomandibular, por exemplo: a Silastic, uma borracha de silicone, que foi relacionada a complicações e resultados pobres, além de reações de corpo estranho e erosões condilares e também o Protoplast/Teflon que é a forma porosa do Teflon, por apresentar propriedades corrosivas desfavoráveis e reações teciduais inaceitáveis como osteólise resultante de partículas soltas pelo desgaste, ocasionando reações de corpo estranho que destruíram a anatomia de muitas ATMs, culminando, em muitos casos, perda da função mandibular.

Já Menconça et al. (2011), fazem referência a um caso de fraturas no terço médio da face comprometimento do arco zigomático direito no qual optou-se pela redução das fraturas por meio de intervenção cirúrgica com fixação de placas e parafusos de titânio. Ao final, obteve-se êxito no procedimento, e evidenciou-se que que o cirurgião deve dominar a anatomia do local e também aplicar meticulosamente a técnica cirúrgica para que as estruturas vásculo-nervosas não sejam danificadas, principalmente com as estruturas do terço médio da face, já que essas possuem relação com outras estruturas faciais importantes e, se houver inadequada interferência, podem gerar sequelas e complicações.

Segundo Silva (2017), o aço inoxidável apresenta favoráveis propriedades mecânicas além de possui fácil processamento e grande disponibilidade, sendo viável principalmente para a fixação de próteses. Verificou-se que os implantes de ligas de aço 316L não apresentam resistência adequada à corrosão, situação que gerou debates acerca do seu uso devido à 
presença de níquel e sua toxicidade, podendo causar alergias e atividades genotóxicas ou mutagênicas. Além disso, materiais cerâmicos apresentam boa biocompatibilidade e favorecem a interação entre o implante e o sítio cirúrgico, no entanto, evidencia-se baixa resistência mecânica para suportar cargas estáticas e dinâmicas, situação que deve ser analisada ao realizar o planejamento cirúrgico. Estudos demonstram que a hidroxiapatita e silicatos na forma de biovidros e vitrocerâmicos, são capazes de estimular a regeneração tecidual por meio da resposta do meio hospedeiro ao reconhecer o material como semelhante ao tecido natural, situação que favorece o processo de ósseo-integração.

Assim como a cerâmica, o titânio e suas ligas também se apresentam como biomateriais favoráveis em cirurgias reconstrutivas a biocompatibilidade e ao favorecimento de ósseo-integração. Os óxidos de alumínio (alumina) e de zircônio (zircônia) são também apresentam biotolerância pelo sistema do receptor e mantém suas propriedades físico-químicas, estruturais e mecânicas sem provocar nenhuma resposta adversa por parte do tecido ósseo. Os vidros bioativos em associação com íons $\mathrm{Si}^{4+}, \mathrm{Ca}^{2+}$ e $\mathrm{PO}_{4}^{3-}$, presentes no Bioglass ${ }^{\circledR}$ 45S5 estimulam a expressão de diversos tipos de genes de células osteoblásticas favorecendo a angiogênese in vitro e in vivo. Percebe-se que esse material apresenta baixa resistência à fratura e restrita usinabilidade, no entanto, essa situação pode ser compensada com a utilização de tratamentos térmicos para nucleação e crescimento dos cristais vítreos, modificando suas propriedades físico-químicas e estruturais, mas, em contrapartida diminuindo o índice de bioatividade (Silva, 2017).

Os scaffolds apresentam-se como um bom biomaterial por fornecer uma matriz biocompatível com porosidade, estrutura tridimensional, degradabilidade, propriedades mecânicas e de transporte de massa adequadas que se assemelham à matriz extracelular. Além disso, incluindo eles apresentam também a capacidade de estimular o crescimento, a migração, a interação e a diferenciação celular ao disponibilizar fatores de crescimento e outros sinais bioquímicos apropriados às células por meio de incorporação ou absorção (Pires et al. (2015).

Zhang et al. (2019), expõe assuntos importantes e que devem ser melhores estudados a fim de melhorar a realidade da reconstrução cirúrgica, como a construção de scaffolds metálicos com células revestidas e substâncias ativas de osteoblasto, realizando a combinação da resistência dos scaffolds metálicos com a indutividade das células e componentes ativos para que possam cumprir a função de scaffolds metálicos ativos. Segundo França et al. (2005), evidenciou-se que apesar da ocorrência de menor integração dos compósitos em relação aos controles, a histomorfometria do tecido de dentro dos poros mostrou perfeita similaridade ao da interface. Os compósitos produzidos revelaram biocompatibilidade, similar aos controles (Medpor ${ }^{\circledR}$ e Polipore ${ }^{\circledR}$ ) e apresentaram maior interatividade com o tecido hospedeiro e menor reação inflamatória. Também foi notada nos compósitos a precipitação de camada com elevado índice de íons cálcio e fósforo na interface do implante com o tecido, sugestivo da presença de hidroxiapatita carbonatada.

Segundo Martin-del-Campo et al. (2019), o uso de compostos de baixo peso molecular, como os derivados de ácido fólico e cátions bioativos, constitui uma alternativa promissora ao uso de fatores de crescimento à base de proteínas e morfógenos, para a preparação de scaffolds reabsorvíveis no modelo de defeito maxilar para permitir a osteocondução e osteoindução nos defeitos. Nesse sentido, o uso de biocerâmicas são atualmente considerados como a alternativa mais promissora para a regeneração de Fissura labial, com ou sem fenda palatina (CL/P), além disso, tecnologias emergentes de bioimpressão em combinação com processos de eletrofiação ou criogelação, permitiram o desenvolvimento de novos substitutos de tecido com um controle preciso de tamanhos e formas para recriar a complexa microestrutura fisiológica, biomecânica e hierárquica de tecidos biológicos que são necessários para a regeneração de malformações como CL/P.

Sabe-se que muitos genes estão envolvidos na regulação do processo de cicatrização de feridas, e com a tecnologia CRISPR-Cas9 é possível realizar a edição de genes para projetar o microambiente da ferida. Desse modo, com o aprofundamento de pesquisas, tem-se como objetivo o alcance de propriedades de cicatrização de feridas fetais em feridas em 
adultos, possibilitando uma completa de cabelos e glândulas sem atrasos e cicatrizes (Das et al. 2016).

Como pontuando por Colazo et al. (2019), os pesquisadores devem buscar trabalhar conjuntamente com cirurgiões clinicamente ativos, observando os tipos de tecnologias necessárias para atender aos pacientes e as diferentes situações clínicas, visto que há muitas opções de materiais e procedimentos. Além disso, percebe-se que as novas tecnologias têm o potencial de diminuir o tempo operatório, o que resulta em maior possibilidade de fornecer cuidados médicos a mais pacientes e um melhor atendimento individual devido à redução da morbidade do local doador, logo a escolha do procedimento deve ser muito bem analisada.

De acordo com de Paula et al. (2017), ao utilizar o biomaterial Alloderm ${ }^{\circledR}$ - material derivado de tecido dérmico humano, sendo sintetizado a partir da derme de cadáveres humanos, bastante conhecido como um substituto alógeno em periodontia. Assim, as principais indicações estão no tratamento de deformidades da crista alveolar, procedimentos de recobrimento radicular, remoção de pigmentação melânica, regeneração óssea guiada e aumento da espessura de tecido queratinizado ao redor de dentes ou implantes. Desse modo, por muito tempo o Alloderm ${ }^{\circledR}$ foi o substituto ao enxerto autógeno mais utilizado na odontologia em razão da sua alta similaridade biológica com os tecidos do paciente, custo razoável e fácil manipulação. Contudo, está em desuso atualmente em alguns países devido às dificuldades de importação e implantação. O biomaterial MucoMatrixX® é sintetizado a partir da derme suína, o produto é submetido a múltiplos processos de limpeza químicos e físicos que removem antígenos e outros contaminantes. Assim, atua dando suporte para a regeneração do tecido conjuntivo, uma vez que promove a revascularização e a integração tecidual. Contudo, existem poucos estudos na literatura elucidando a aplicabilidade da MucoMatrixx®.

Os principais biomateriais aplicados na cirurgia craniomaxilofacial, segundo Turrer et al (2008), são os metais amplamente utilizados em próteses e como elementos estruturais na estabilização de fraturas ósseas devido a facilidade de fabricação e o baixo custo, sendo a principal escolha para tratamento de fraturas ósseas, e os polímeros em decorrência de sua capacidade de sofrer deformação plástica para absorver a energia de um impacto antes de ocorrer a fratura do material. Ademais, o estudo apontou o maior obstáculo em relação aos biomateriais é o grande custo resultante de não serem manufaturados no Brasil, situação que carece de pesquisas e maiores investimentos. A procura por melhor biointegração entre os materiais disponíveis vem estimulando investigações científicas a respeito dos compósitos para associação de componentes com propriedades diferentes para desenvolver uma melhor adaptação ao local receptor.

\section{Conclusão}

Biomateriais são, portanto, quaisquer substâncias - sintéticas ou naturais - ou uma combinação destas, desde que não sejam drogas, que são usadas por determinado tempo no organismo para aumentar ou substituir algum tecido ou órgão ou restabelecer as funções corporais. Eles devem ser biocompatíveis, a fim de não gerar nenhuma resposta infecciosa ou alérgica no organismo, por meio da mobilização de macrófagos. É importante frisar que o uso de biomateriais é favorável para o médico e para o paciente. Contudo, a escolha do melhor material requer uma avaliação individual de cada paciente e o resultado também é dependente da escolha adequada da técnica cirúrgica adotada. Assim, cabe ao profissional distinguir a real necessidade de cada paciente, respeitar a limitação pessoal deste e da intervenção, além de se ater à biocompatilidade, funcionalidade, leveza, adaptabilidade, estabilidade, resistência à corrosão do biomaterial escolhido para aperfeiçoar o processo regenerativo. Por fim, cabe ressaltar, ainda, que, no Brasil, o uso dos biomateriais enfrenta objeções como o elevado custo por não serem manufaturados no país. 
Research, Society and Development, v. 10, n. 12, e03101220139, 2021

(CC BY 4.0) | ISSN 2525-3409 | DOI: http://dx.doi.org/10.33448/rsd-v10i12.20139

\section{Referências}

Anderson, J. M., Rodriguez, A. \& Chang, D. T. (2008). Foreign body reaction to biomaterials. In: Seminars in immunology. Academic Press, 86-100.

Barbosa, M. C. S. S., Kinoshita, A. M. O. \& Silveira, E. M. V. (2018). Biomateriais utilizados em artroplastia parcial ou total da articulação temporomandibular: uma revisão de literatura. Salusvita, 37 (2), 389-403.

Castro, E. K. O. \& Nogueira, E. A. A. (2018). Considerações atuais sobre o uso de biomateriais em cirurgia de levantamento de soalho do seio maxilar: Revisão de Literatura. Tese (Trabalho para obtenção do Título de Cirurgião-Dentista) - Centro Universitário São Lucas. Porto Velho.

Claudino, J. \& Alves, L. A. C. (2019). Biomateriais: uma realidade para as cirurgias de enxerto em Odontologia-revisão da literatura. J Health Sci Inst, 37 (2), 174-178.

Colazo, J. M., Evans, B. C., et al. (2019). Applied Bioengineering in Tissue Reconstruction, Replacement and Regeneration. Tissue Engineering, 25 (4), 259290.

Colombo, L. R. C., et al. (2011). Biomateriais para reconstrução da órbita: revisão de literatura. Rev. Bras. Cir. Plást., 26 (2), $337-344$.

Das, S. \& Baker, A. B. (2016). Biomaterials and nanotherapeutics for enhancing skin woud healing. Frontiers in Bioengineering and Biotechnology, 4 (82), 120.

França, V. P., Figueiredo, A. R. P. D., Vasconcelos, A. C., \& Oréfice, R. L. (2005). Estudo comparativo experimental de compósito bioativo de matriz polimérica para aplicação em cirurgia plástica ocular na substituição tecidual. Arquivos Brasileiros de Oftalmologia, 68 (1), $425-431$.

Horn, K. S. (2011). O uso de biomateriais em implantes fenestrados: uma revisão atual. Tese (Trabalho para obtenção do Título de Cirurgião-Dentista) Universidade Federal do Rio Grande do Sul. Porto Alegre.

Júnior, J. C. R. et al. (2021). Uso de matriz de colágeno para tratamento de recessão gengival RT1. Revista Sul Brasileira de Odontologia RSBO, 18 (1):165172

Leal, T. R., Cacêdo Filho, R. A., Leal, A. R. R. \& Coury, R. M. (2016). O uso de biomateriais em cirurgia de reconstrução periodontal. Anais I CONBRACIS.

Maia, M., et al. (2010). Reconstrução da estrutura facial por biomateriais: revisão de literatura. Rev. Bras. Cir. Plást., 25 (3), $566-572$.

Martín-del-Campo, M., Ibanez, R. S. \& Rojo, L. (2019). Biomaterials for Cleft Lip and Palate Regeneration. International Journal of Molecular Sciences, 20 (2176), 1-10.

Matta, R. K. A., et al. (2020). Atualidades na reconstrução fronto-orbital: relato de caso. Brazilian Journal of Health Review, 3 (2), $1778-1785$.

Mendonça, J. C. G. et al. (2011). Tratamento de fraturas complexas do terço médio da face: relato de caso. Rev Bras Cir Craniomaxilofac, 14 (4), $221-224$.

Leite, W. B., Silveira, E. M. V. \& Kinoshita, S. O. (2018). Biomateriais utilizados em artroplastia de quadril. Lusvita, 37 (4), $953-962$.

Paula, B. L., Rodas, M. A., De Souza Gonçalves, A. C., Dos Santos, Y. D. S. \& Varize, E. M. (2017). Biomateriais utilizados em substituição ao enxerto autógeno de gengiva. Braz.J Periodontol, 27 (1).

Pilger, A. D., Schneider, L. E., Da Silva, G. M., Schneider, K. C. C. \& Smidt, R. (2018). Biomateriais de substituição óssea para procedimentos de reconstrução alveolar em implantodontia. Revista de Ciências Médicas e Biológicas, 17 (1), 102-107.

Pires, A. L. R., Bierhalz, A. C. K. \& Moraes, A. M. (2015). Biomateriais: tipos, aplicações e mercado. Química Nova, 38 (1), $957-971$.

Rafael Júnior, J. C., Siqueira, N. C., Mazorra, P. C., Pfau, V. J. M. \& Pfau, E. A. (2020). Uso de matriz de colágeno para tratamento de recessão gengival RT1. Revista Sul Brasileira de Odontologia RSBO, 18 (1), 165-172.

Rodrigues, L. B. (2013). Aplicação de biomateriais em ortopedia. Estudos Tecnológicos em Engenharia, 9 (2), 63-76.

Rodrigues, W. J. P. R. (2014). Uso de biomateriais nas abordagens cirúrgicas minimamente invasivas para tratamento de defeitos ósseos periodontais: revisão sistemática. Biblioteca Virtual em Saúde. Rio de Janeiro, 1-66.

Signori, P. H., Giacomin, M., Ferreira, C. J., De Conto, F., Sawazaki, R. \& Tonietto, L. (2016). Uso de diferentes biomateriais no tratamento de fraturas de assoalho de órbita: Colégio Brasileiro de Cirurgiões, 5 (1), 1-9.

Silva, V. V. (2017). Aplicação De Biomateriais Em Ortopedia E Engenharia De Tecido Ósseo: Revista Saúde E Meio Ambiente, 5 (2), $14-27$.

Turrer, C. L. \& Ferreira, F. P. M. (2008). Biomateriais em cirurgia craniomaxilofacial: princípios básicos e aplicações: revisão de literatura. Revista Bras. Cir. Plást, 23 (3), 234-239.

Turrer, C. L. et al. (2008). O uso de implantes de compósito bioativo de biocerâmica em matriz polimérica na reconstrução do complexo zigomático orbitário: novas perspectivas em biomateriais. Arq Bras Oftalmo.,71 (2), 153-161.

Zhang, Q., Wu, W, et al. (2019). Advanced biomaterials for reparing and reconstruction of mandibular defects. Materials Science \& Engigeering, 19 (3). 